\title{
Conceptualizing Stakeholders' Perceptions of Ecosystem Services: A Participatory Systems Mapping Approach
}

\author{
Rita LOPES, Nuno VIDEIRA* \\ CENSE - Center for Environmental and Sustainability Research, Department of Environmental Sciences \\ and Engineering, Faculty of Science and Technology, Universidade NOVA de Lisboa, Portugal 2829-516, \\ Caparica, Portugal
}

\begin{abstract}
A participatory system dynamics modelling approach is advanced to support conceptualization of feedback processes underlying ecosystem services and to foster a shared understanding of leverage intervention points. The process includes systems mapping workshop and follow-up tasks aiming at the collaborative construction of causal loop diagrams. A case study developed in a natural area in Portugal illustrates how a stakeholder group was actively engaged in the development of a conceptual model depicting policies for sustaining the climate regulation ecosystem service.
\end{abstract}

Keywords - Participatory systems mapping; ecosystem services/climate regulation; stakeholders' perceptions; causal loop diagrams

\section{INTRODUCTION}

Ecosystem services are the benefits people obtain from nature [1]. This concept has been increasingly used in research and policy agendas over the last decade, fostered by major studies and initiatives such as the Millennium Ecosystem Assessment [1], The Economics of Ecosystems and Biodiversity [2] and, more recently, the Intergovernmental Platform on Biodiversity and Ecosystem Services (IPBES). Several authors have been debating the use of this concept [3], how it should be integrated in decision-making processes [4] and how to foster articulation of multiple values of ecosystem services [5], [6].

Understanding the concept of ecosystem services and its applicability in different contexts can be defined as an "unstructured problem" [7]. Such designation refers to complex and less studied subjects, with uncertainties in the available scientific knowledge and disagreements on norms and values at stake. These problems typically call for a "policy as learning" approach and a high level of stakeholder participation. This is the case with complex environmental and sustainability problems, often characterized by high scientific uncertainties, multiple interrelationships, non-linear dynamics, large-scale consequences and irreversible damages [8].

Participatory Systems Mapping (PSM) emerges in this context as a promising approach to address complex and unstructured problems through a participatory system dynamics modelling process [9], [10]. PSM can be defined as the preparation and development of group model building activities, engaging stakeholder groups in the construction of causal loop diagrams (CLDs) to deliver insights regarding a specific issue and foster knowledge exchange [11]. Some authors have recently been applying this approach to different environmental and sustainability issues. Videira et al. [12] mapped maritime problems with maritime stakeholders, Sedlacko et al. [11] used a PSM approach for sustainable consumption and Videira et al. [13] conducted an

\footnotetext{
* Corresponding author.

E-mail address: nmvc@fct.unl.pt
} 
exploratory study aiming to improve understanding on degrowth pathways through collaborative causal models. These examples were used to promote involvement of broad participant groups in environmental and sustainability debates, using system dynamics conceptualization tools, namely causal loop diagrams.

CLDs were developed since the 1960's and have been used for communication of feedback processes in complex systems using the system dynamics modelling language [14]-[16]. The development of CLDs has the goal of defining a dynamic hypothesis regarding what can happen if a certain change within a system takes place. The conceptual nature of a CLD allows drawing a causal chain of effects sketched along a string of variables describing a dynamic issue, thus showing the relevant feedback structure of the problem being studied. The production of CLDs in participatory contexts generates an open learning platform, structuring the deliberative process and fostering the co-production of knowledge [11], [12].

Within this background, this paper presents an innovative approach for conceptualizing stakeholders' perceptions on the complex feedback structure underlying the provision of ecosystem services. We combine a PSM workshop informed by preparatory problem scoping activities with a comprehensive diagram postproduction process. The expected contribution is twofold: 1) an approach to understand feedback processes underlying management of ecosystem services, and how the preservation of a specific service is linked with others; and 2) a procedure to identify options describing key management mechanisms for a specific area in order to allow for a sustainable flow of ecosystem services.

The proposed methodology was tested in Arrábida Natural Park, a Portuguese natural area with protected coastal and marine ecosystems. We invited stakeholder groups to collaborate in the development of CLDs addressing different ecosystem services identified in the park. Here, we will illustrate the methodology with results achieved for the "climate regulation" ecosystem service. This service underpins one of the main issues addressed in international climate negotiations [17], and was essentially translated into carbon vegetation sequestration and storage. $\mathrm{CO}_{2}$ emissions through deforestation, biomass burning, wetlands drainage, soil tillage and sealing of natural ecosystems are very significant and constitute about $20 \%$ of the worldwide anthropogenic emissions [18]. Land use change also leads to service loss, impacting the future carbon sequestration and storage service by terrestrial ecosystems. With the collaboration of local participants, we aimed to identify such drivers of change, and the interplay between management policies able to provide a sustainable flow of the service in this area.

The paper is organized in five sections. Section 2 details the methodological approach, while in Section 3 we present and discuss the results of the participatory systems mapping process. The evaluation of the process by participants is presented in Section 4. Finally, Section 5 concludes with a synthesis of the main findings and lessons learned.

\section{Methods ANd PARTicipatory Systems MAPPING SCRIPT}

The proposed participatory modelling process leading to the conceptualization of stakeholders' perceptions of ecosystem services takes place in two distinct steps: a PSM workshop and a postproduction stage aiming to integrate different knowledge sources. Two complementary steps bookend these activities, namely problem scoping tasks gathering information to set the scene for the mapping workshop, and follow up procedures to prepare outcomes for subsequent ecosystem services assessment and valuation studies (Fig. 1). 


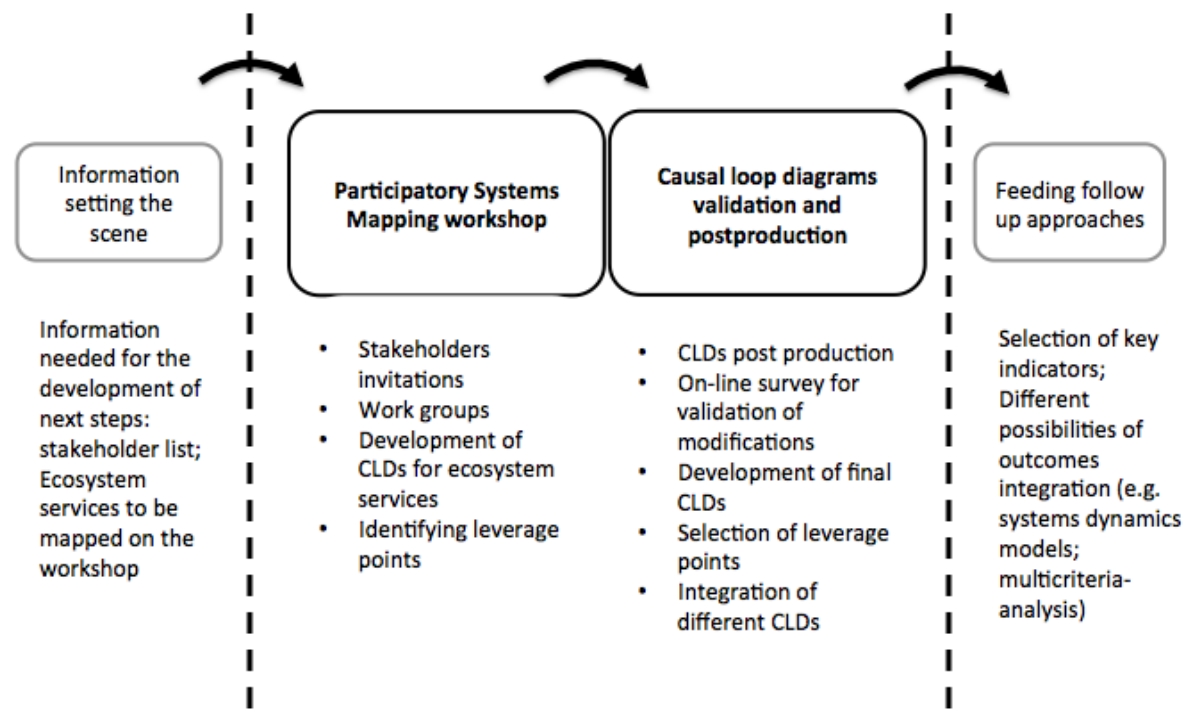

Fig. 1. Methodology for participatory systems mapping of ecosystem services.

To set the scene for the PSM workshop, a collaborative scoping process of ecosystem services is suggested [5], [19]. At this stage, information is collected on the relevant institutional setting and stakeholder groups acting in the study area, who may then be invited to identify a relevant set of ecosystem services, drivers of change, and linkages with human wellbeing. Results from this preparatory stage support the PSM workshop by providing a list of relevant ecosystem services to be mapped, along with potential variables associated with each service.

The participatory systems mapping workshop involves the collaborative construction of CLDs representing the structure underlying the provision of specific ecosystem services. The innovative features of this approach lie on the elicitation of stakeholders' perceptions of ecosystem services dynamics, using this concept to structure the discussion and to understand interactions in socio-ecological systems. This is expected to promote a better understanding on the management options for the delivery of a sustainable flow of ecosystem services.

Diagramming tools such as CLDs allow capturing participants' perceptions and mental models [15]. CLDs facilitate the representation of the feedback mechanisms underlying the unstructured issue by using elements such as variable names and arrows representing causal links between two variables. Causal links can be positive (a "+" sign is used) if the variables change in the same direction, or negative (a "-" sign is used) if the variables change in opposite direction. The set of links can form feedback loops, which in turn can be designated as reinforcing or balancing loops [15].

For the construction of CLDs in groups we propose following the methodology presented by Vennix [20], according to which participants identify a problem variable, add causes and consequences and then identify feedback loops linking consequences and causes. Here, the structural mapping process is also guided by a leading question that fosters alignment of participants' perceptions with a common goal and draws a comparable baseline for mapping different ecosystem services. Table 1 presents the script developed for conducting a PSM workshop for the conceptualization of ecosystem services. 


\section{TABLE 1. SCRIPT OF A PARTICIPATORY SYSTEMS MAPPING WORKSHOP ADDRESSING ECOSYSTEM SERVICES (TEMPLATE SOURCE: ADAPTED From [21])}

\begin{tabular}{|c|c|}
\hline Description & Script for conducting a participatory systems mapping process for ecosystem services. \\
\hline Script Status & Promising practice. \\
\hline Context & $\begin{array}{l}\text { This script is meant to be used in the context of a participatory systems mapping workshop aiming } \\
\text { to build conceptual models depicting dynamics of ecosystem services. Construction of CLDs is } \\
\text { envisaged with engagement of participants from broad stakeholder groups. }\end{array}$ \\
\hline Purpose & $\begin{array}{l}\text { Framing the problem and initiating systems mapping } \\
\text { Eliciting variables } \\
\text { Eliciting feedback loops }\end{array}$ \\
\hline $\begin{array}{l}\text { Primary nature } \\
\text { of group task }\end{array}$ & Convergent (activity designed to clustering and categorizing ideas and interpretations) \\
\hline Time & $\begin{array}{l}\text { Preparation time: approximately } 2 \text { months } \\
\text { Time required to complete steps in script: approximately } 4 \text { hours (extendable) } \\
\text { Follow up time: approximately } 1 \text { month (extendable) }\end{array}$ \\
\hline $\begin{array}{l}\text { Materials } \\
\text { needed to } \\
\text { complete } \\
\text { script }\end{array}$ & Markers, flip charts, cards or post-its, computer, overhead projector. \\
\hline $\begin{array}{l}\text { Inputs from } \\
\text { other scripts }\end{array}$ & Initiating and elaborating a causal loop diagram [20]. \\
\hline $\begin{array}{l}\text { Outputs from } \\
\text { this script }\end{array}$ & $\begin{array}{l}\text { Causal loop diagrams representing different ecosystem services (exact number depends on specific } \\
\text { goals and size of participant group). }\end{array}$ \\
\hline $\begin{array}{l}\text { Team roles } \\
\text { required and } \\
\text { expertise } \\
\text { needed }\end{array}$ & Facilitator and modellers with experience in system dynamics and causal loop diagramming. \\
\hline $\begin{array}{l}\text { Who is in the } \\
\text { room? }\end{array}$ & $\begin{array}{l}\text { Research/modelling team, including a facilitator who helps in construction of CLDs and one or } \\
\text { more modellers and recorders who translate CLDs on system dynamics software to show to all } \\
\text { participants at the end of the workshop; } \\
\text { Participants representing broad stakeholder groups. }\end{array}$ \\
\hline Key steps & $\begin{array}{l}\text { Step } 1 \text { - Briefing presentation }(20-30 \mathrm{~min}) \\
\text { Purpose: Familiarize participants with ecosystem services concepts, including the information } \\
\text { collected at preparatory stage regarding the ecosystem services to be mapped at the workshop. Give } \\
\text { explanations on the method to be used, presenting concrete examples on the development of the } \\
\text { CLDs. } \\
\text { Role of modelling team: provide an overview of diagramming methods and the workshop process, } \\
\text { giving room for participants' questions and emphasizing the leading question which guides the } \\
\text { model building process. }\end{array}$ \\
\hline
\end{tabular}

Step 2 - Work in small groups: development of CLDs (70-90 min)

Purpose: Organize working groups, each of them dealing with a specific ecosystem service and develop the underlying dynamics. Example of leading question: "How to ensure a sustainable flow of ecosystem service X over the next 20 years"?

Role of research team: Assist participants in the configuration of small groups comprising participants from different stakeholder organizations, and in the designation of a rapporteur in each small group. A paper worksheet (size A1) is delivered and placed at the centre of each small group's working table. Cards/post-its and A4 sheets with information on systems mapping methods and examples of variables are distributed.

Role of participants: Participants select the thematic working group that they would like to join. Rapporteurs are responsible for moderating small group discussions and presenting results to the whole group in plenary discussions. Small group participants identify the possible causes and consequences of "the problem" (i.e., underlying the leading question) and mark the polarity of causal relationships established. After identifying the feedback loops, participants select the key leverage intervention points in the CLD to address the main question. 


\begin{tabular}{|c|c|}
\hline & $\begin{array}{l}\text { Step } 3 \text { - Plenary discussion and debriefing ( } 30-60 \mathrm{~min}) \\
\text { Purpose: Presentation of the CLDs developed in small groups to all participants. Identification of } \\
\text { interrelationships between CLDs. Debriefing of main results and lessons learned. } \\
\text { Role of research team: Translate CLDs to system dynamics software, identify interrelationships } \\
\text { between CLDs and conduct debriefing of results. } \\
\text { Role of participants: Rapporteur from each group presents the final CLD to all the audience and the } \\
\text { selected leverage points. All participants are invited to plenary discussion of results and lessons } \\
\text { learned. }\end{array}$ \\
\hline $\begin{array}{l}\text { Evaluation } \\
\text { criteria }\end{array}$ & $\begin{array}{l}\text { The modelling team distributes an evaluation questionnaire to collect participants' opinions } \\
\text { regarding the workshop and the PSM approach. Evaluation allows to determine effects of the } \\
\text { process according to different criteria and levels of impact: individual (e.g. reaction and learning), } \\
\text { group (e.g., communication); organizational (e.g., impact on decision rules) and methodological } \\
\text { (e.g., usefulness of results and methods). }\end{array}$ \\
\hline Authors & Lopes and Videira [19] \\
\hline $\begin{array}{l}\text { History \& } \\
\text { basis for script }\end{array}$ & $\begin{array}{l}\text { Framework for the participatory articulation of ecosystem services values [5] - Phase 2: developing } \\
\text { a deeper understanding of the dynamics and feedback processes underlying sustainable flows of } \\
\text { ecosystem services. }\end{array}$ \\
\hline Revisions & Not yet revised. \\
\hline References & {$[12],[20]$} \\
\hline
\end{tabular}

The postproduction stage follows the PSM workshop and aims to iterate and improve the quality of CLDs developed in the group model building session. While respecting the structure developed by participants, this task fosters the production of revised CLDs addressing, for example, inconsistencies, duplicities and under-developed structures observed in the diagrams from PSM sessions [11]. The modelling team conducts such tasks "behind-the-scenes" and then returns the CLDs back to stakeholders for validation.

We advocate that two distinct editing tasks may be needed. First, a format editing, which includes the digitalization of the CLDs (e.g., using Vensim ${ }^{\mathrm{TM}}$ software) made by the modelling team. For example, incorporating small changes in variable names or in the identified causal relationships. We propose a set of rules (Table 2) according to the good practices for drawing a CLD developed by Sterman [16]. This formatting edits allow to improve formal issues in the diagrams and to use a common layout for all CLDs developed by different working groups.

TABLE 2. RULES FOR POSTPRODUCTION OF CLDS (ADAPTED FROM [16])

\begin{tabular}{|c|c|}
\hline Type of adjustment & Rules for modification \\
\hline Variables & $\begin{array}{l}\text { - Variables should be described through names and without prefixes } \\
\text { (change as necessary). } \\
\text { - Identification of intermediate variables (include as necessary). } \\
\text { - Level of aggregation (aggregation and split of variables). } \\
\text { - Standardization of variable names repeated in several CLDs (change } \\
\text { as necessary). }\end{array}$ \\
\hline Causal links & $\begin{array}{l}\text { - Identification of relationships between variables that were missing in } \\
\text { the original CLD. } \\
\text { - Identification of the polarity of relationships (when missing). } \\
\text { - Identification of feedback loops. }\end{array}$ \\
\hline
\end{tabular}

A revised version of the diagram may then be sent back to participants through an online survey (e.g., using Google docs). The goal is to validate the changes made in the CLD and to give participants the opportunity to reflect upon the dynamic hypothesis and to introduce potential modifications that they did not think of during the workshop. This survey may also allow validating the identified leverage points.

Format editing may be complemented by some degree of content editing in order to integrate knowledge based on expert consultation or literature review. Similarly, this may be reported 
back to participants for validation or for comparing results from the stakeholders' system map with documented knowledge on key variables and causal relationships. Moreover, when different CLDs are produced in separate working groups, it is useful to build an integrated systems map depicting the potential interrelationships established between several ecosystem services. This also supports the analysis of how a specific intervention in one part of the system may affect more than one ecosystem service, as well as performance evaluation of alternative management strategies.

Finally, results from the PSM process may be used to deepen understanding on the dynamics of ecosystem services and support policy-making processes. Follow-up options may include defining and measuring ecosystem service indicators, building simulation models for policy analysis and/or evaluating alternatives with multicriteria analysis methods.

\section{RESULTS AND DiSCUSSION}

\subsection{Arrábida Natural Park}

The proposed methodology was applied in Arrábida Natural Park, a coastal and marine protected area in Portugal created in 1976. The area is characterized by Mediterranean climate with two distinct seasons, one hot and dry and the other cold and rainy [22]. The nature of the protected area allows for an intense human presence that contributes with several management issues, as the Natural Park presents different land uses across the territory. According to Fumega [22], based on data from EEA [23], Arrábida Natural Park presents discontinuous urban fabric, industrial and commercial units, mineral extraction sites, non-irrigated arable land, permanently irrigated land, vineyards, olive groves, complex cultivation patterns, land principally occupied by agriculture, with significant areas of natural vegetation, agro-forestry areas, broad-leaved forest, coniferous forest, mixed forest, Sclerophyllous vegetation, transitional woodland-shrub and bare rocks. Inside the Natural Park area, a cement industry is the major individual source of emissions in the area, with an annual average of $1200 \mathrm{Gg} \mathrm{CO}_{2}$ emissions between 2010-2014 [24]. The variety of land uses, the strong human presence, the touristic component and the pollutant activities all compound to make this natural area suitable for the implementation of the proposed methodology, while looking for different narratives and management options on how a sustainable flow of ecosystem services could be made possible.

At a preliminary stage, we have conducted a scoping exercise in the Arrábida Natural Park [19], which framed the application of the methodology for conceptualization of ecosystem services presented in this paper. The preparatory tasks allowed for outlining the key four ecosystem services to be mapped in the PSM workshop: food production, biodiversity and recreation, eco-tourism, and climate regulation. For illustrative purposes, in this paper we selected the climate regulation ecosystem service as an applied example of the proposed PSM approach described in the next sections. This service belongs to the category of "regulation services", responsible for regulating ecosystems (e.g., water regulation, air quality regulation, erosion regulation, pollination, human disease and pest regulation). In particular, according to local stakeholders, the climate regulation service in the Arrábida Natural Park is translated into control of rain/humidity and carbon sequestration, which influences biomass close to the soil. According to stakeholders consulted at the scoping stage, the main driver of change for this service is perceived to be land conversion, for example as a consequence of forest fires. 


\subsection{Climate Regulation Reference Mode}

Climate regulation is the service provided by ecosystems through controlling the flux of greenhouse gases - GHG (mainly carbon dioxide), contributing to carbon sequestration and storage through several mechanisms [25]. Carbon circulates permanently, in various chemical states, between the atmosphere, the biosphere, the lithosphere and the hydrosphere. Gaseous exchanges are thus made in the interface of various natural ecosystem types (e.g., forests, grasslands, oceans, wetlands.). Carbon dioxide $\left(\mathrm{CO}_{2}\right)$ is a gas mixed in the atmosphere, and the global climate regulation service benefits all humans, regardless of where the beneficiaries are located. The loss of this service is a function of direct habitat destruction, and depends on the types of ecosystems affected.

Increased emissions of GHGs may result from certain land use changes, such as the cultivation of previously undisturbed soils, peat extraction or the production of methane by ruminant livestock, amongst others. Management of ecosystem uses may also reduce emissions through removals, for example, via forest planting [25]. Hence, the main drivers of change within the land use change category are expansion, conversion or abandonment of productive area, urbanization and artificial sealed surfaces [25]. Some authors have been modelling the climate regulation service globally, looking for the possibility to map its economic value and relative changes under different scenarios of ecosystems and land use change [2].

Based on the literature, we defined the reference mode for this ecosystem service (Fig. 2) for Portugal including two key variables: a) total GHG emissions and b) total GHG removals from the land use, land use change and forests sector (LULUCFs). We characterized the historical trend taking into account the national emissions and removals reported to date [26].

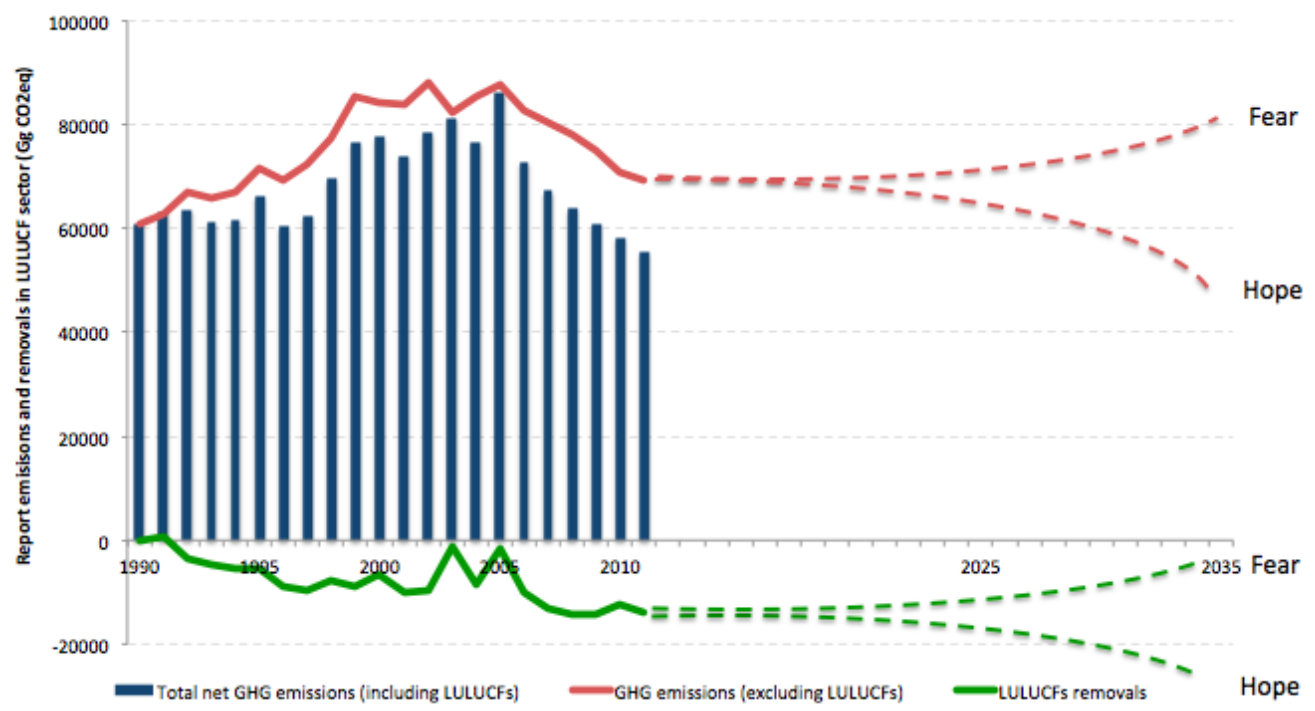

Fig. 2. Climate regulation reference mode (Data from [26]; "Hopes and fears" pathways adapted from the approach proposed by [27]).

Total emissions (excluding LULUCF's) include several sectors, such as energy production, industrial processes, solvents and use of other products, agriculture and waste. The emissions are represented in $\mathrm{CO}_{2} \mathrm{eq}$ and include carbon dioxide, methane, nitrous oxide and fluorinated gases. 
The reference mode presented in Figure 2 captures the evolution at the national context of the net GHG emissions (blue bars), with and without the LULUCFs removals (red and green lines, respectively). Following Otto and Struben [27] we hypothesized a "Hopes and Fears" exercise, adding two possible broad pathways for GHG emissions and for LULUCFs removals until 2035.

\subsection{Participatory Systems Mapping Workshop}

The PSM workshop took place in the district of Setúbal, Portugal, where the Arrábida Natural Park is located. Sixteen participants from different stakeholder groups (e.g., government/administration, research institutions, civil society, business) were gathered during an afternoon. These participants were divided in four groups (see step 2 in table 1) each one developing collaboratively a CLD for a specific ecosystem service.

The mapping exercises in each small working group were guided by the question: "How to guarantee a sustainable flow of provision of the ecosystem service X in the next 20 years?" The group responsible for the climate regulation service produced the CLD illustrated in Fig. 3.

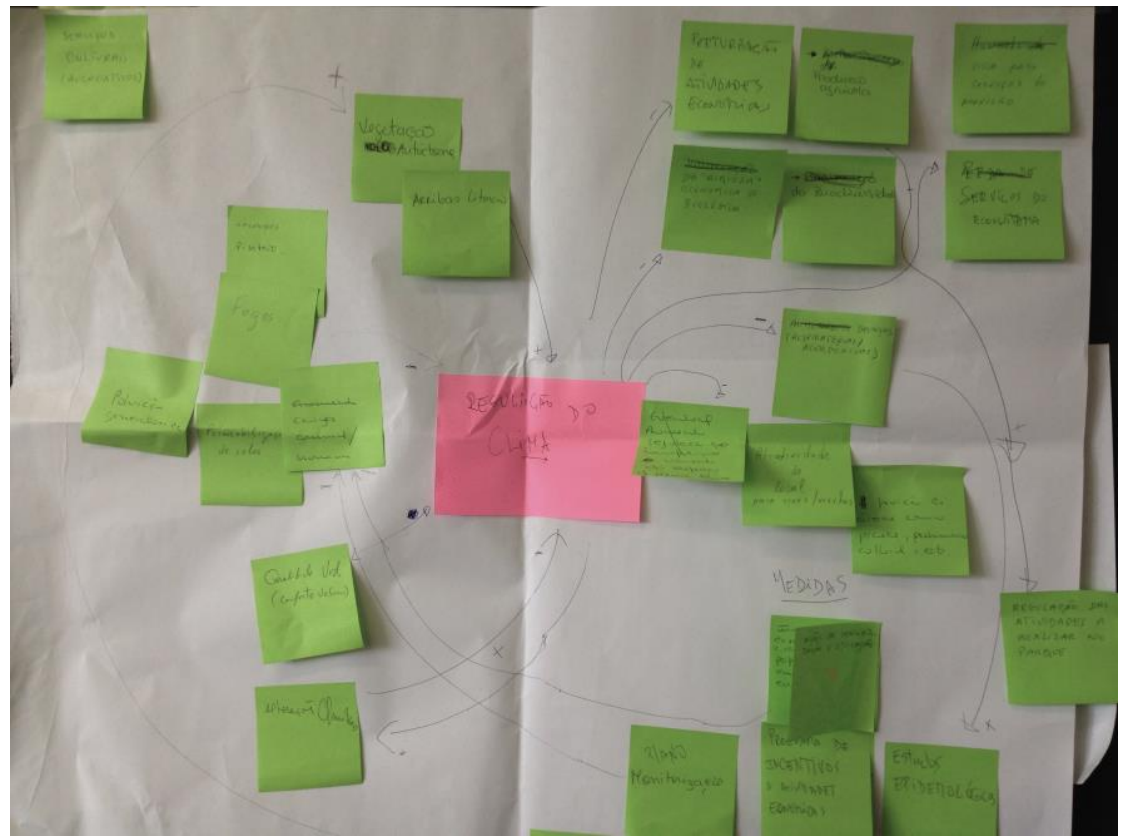

Fig. 3. Picture of the causal loop diagram developed by workshop participants for the climate regulation ecosystem service.

The placement of post it cards show how participants discussed and perceived the management of this ecosystem service in the protected area, following the steps proposed by Vennix [20]. A key variable was placed at the centre of the diagram (pink card) representing the ecosystem service; (green) variable cards to the left hand side were added by participants as drivers of change in ecosystem service supply, and the consequences of those changes were subsequently added to the right hand side. Stakeholder drew the causal links connecting these variables and identified the polarity of the relationships. Finally, they established feedback loops and found intervention points to balance the consequences of negative changes in ecosystem service flows. Participants provided a short description of the meaning of each variable on the 
respective card. The variables depicted in Figure 3 for the climate regulation CLD are presented in detail in Table 3.

\section{TABLE 3. VARIABLES INCLUDED IN THE CLIMATE REGULATION CLD PRODUCED DURING THE} PSM WORKSHOP

\begin{tabular}{lll}
\hline Causes & Consequences & Intervention points \\
\hline - Trampling & - Economic activities disorder & - Habitat conservation program* \\
- Coastal cliffs & - Economic and biological richness & $\begin{array}{l}\text { - Regulatory activities in the } \\
\text { protected area }\end{array}$ \\
- Native vegetation & - Biodiversity & $\begin{array}{l}\text { Awareness and educational } \\
\text { actions* }\end{array}$ \\
- Generalized pollution & - Agricultural output & - Monitoring plan \\
- Fires & - Allergenic and respiratory & \\
- Soil waterproof & diseases & \\
- Animal and human load & - Free use of space & \\
& - Local attractiveness & \\
\hline
\end{tabular}

* Intervention points with more leverage, as voted by participants

As discussed by Vennix [20] in messy and complex situations, people hold very different and mostly open loop views on what the problems are. With the deployed script (Table 1) we enabled the discussion and the convergence on the perceptions about a complex and global issue that needs local awareness and management. The following sections describe the iteration of the CLD constructed during the workshop and the lessons learned from the process.

\subsection{Postproduction and Validation Results}

The CLDs obtained were submitted to a postproduction process in order to promote a comprehensive analysis of the outcomes. The postproduction step was developed in two different steps with distinct goals: i) an online survey that returned the CLDs to participants, which aimed to obtain a validation on changes made on variables and links (format edits) and ii) a further improvement of the CLD based on information collected through a literature review (content edits).

We asked participants to validate the changes made after the workshop and to add some variables or links they considered to be missing. More specifically, the group of participants that worked on the climate regulation CLD agreed on the modifications and did not contribute with additional variables or links. This outcome may indicate that a high degree of consensus among participants of this small working group was achieved during the workshop exercise.

The reviewed ecosystem services literature (e.g., [1], [25]) supported the small content edits produced in the CLD (e.g., aggregation of variables, formalization of causal links and feedback loops, specifying variable names), which allowed for improvements in this system map while retaining the fundamental structure agreed upon by participants (Table 4). 


\section{TABle 4. EXAmples of AdJUSTMENTS MADE to the ORIGINAL CLD DURING THE POSTPRODUCTION PROCESS}

\begin{tabular}{|c|c|c|c|c|c|}
\hline \multicolumn{2}{|c|}{ Problem causes } & \multicolumn{2}{|c|}{ Problem consequences } & \multicolumn{2}{|c|}{ Intervention points } \\
\hline $\begin{array}{l}\text { Original } \\
\text { variable }\end{array}$ & $\begin{array}{l}\text { Adjustments } \\
\text { made }\end{array}$ & $\begin{array}{l}\text { Original } \\
\text { variable }\end{array}$ & $\begin{array}{l}\text { Adjustments } \\
\text { made }\end{array}$ & $\begin{array}{l}\text { Original } \\
\text { variable }\end{array}$ & Adjustments made \\
\hline Trampling & $\begin{array}{l}\text { Habitat } \\
\text { trampling } \\
\text { intensity }\end{array}$ & $\begin{array}{l}\text { Economic } \\
\text { activities } \\
\text { disorder }\end{array}$ & Economic costs & $\begin{array}{l}\text { Habitat } \\
\text { conservation } \\
\text { program* }\end{array}$ & $\begin{array}{l}\text { Habitat } \\
\text { conservation } \\
\text { measures }\end{array}$ \\
\hline Coastal Cliffs & $\begin{array}{l}\text { Vegetation on } \\
\text { coastal cliffs }\end{array}$ & $\begin{array}{l}\text { Economic and } \\
\text { biological } \\
\text { richness }\end{array}$ & $\begin{array}{l}\text { Variable was } \\
\text { deleted }\end{array}$ & $\begin{array}{l}\text { Regulatory } \\
\text { activities in the } \\
\text { protected area }\end{array}$ & $\begin{array}{l}\text { Regulatory } \\
\text { activities in the } \\
\text { protected area }\end{array}$ \\
\hline $\begin{array}{l}\text { Native } \\
\text { vegetation }\end{array}$ & $\begin{array}{l}\text { Native } \\
\text { vegetation }\end{array}$ & Biodiversity & Biodiversity & $\begin{array}{l}\text { Awareness and } \\
\text { educational } \\
\text { actions* }\end{array}$ & $\begin{array}{l}\text { Monitoring, } \\
\text { awareness and } \\
\text { educational } \\
\text { measures }\end{array}$ \\
\hline $\begin{array}{l}\text { Generalized } \\
\text { pollution }\end{array}$ & $\begin{array}{l}\text { Total } \mathrm{CO}_{2} \text { in the } \\
\text { atmosphere }\end{array}$ & $\begin{array}{l}\text { Agricultural } \\
\text { output }\end{array}$ & $\begin{array}{l}\text { Agriculture } \\
\text { output }\end{array}$ & Monitoring plan & \\
\hline Fires & Forest fires & $\begin{array}{l}\text { Allergenic and } \\
\text { respiratory } \\
\text { diseases }\end{array}$ & $\begin{array}{l}\text { Allergenic and } \\
\text { respiratory } \\
\text { diseases }\end{array}$ & & $\begin{array}{l}\text { Technological } \\
\text { measures (added } \\
\text { variable) }\end{array}$ \\
\hline $\begin{array}{l}\text { Soil } \\
\text { waterproof }\end{array}$ & $\begin{array}{l}\text { Variable was } \\
\text { deleted }\end{array}$ & $\begin{array}{l}\text { Free use of } \\
\text { space }\end{array}$ & $\begin{array}{l}\text { Variable was } \\
\text { deleted }\end{array}$ & & \\
\hline $\begin{array}{l}\text { Animal and } \\
\text { human load }\end{array}$ & $\begin{array}{l}\text { Human and } \\
\text { animal GHG } \\
\text { emissions }\end{array}$ & $\begin{array}{l}\text { Local } \\
\text { attractiveness }\end{array}$ & $\begin{array}{l}\text { Area } \\
\text { attractiveness } \\
\text { and quality of } \\
\text { life }\end{array}$ & & \\
\hline & & $\begin{array}{l}\text { Climate } \\
\text { change }\end{array}$ & $\begin{array}{l}\text { Climate } \\
\text { change }\end{array}$ & & \\
\hline
\end{tabular}

The CLD presented in Figure 4 shows the final result, including the combination of outcomes from the PSM workshop and the postproduction activities, revealing the relationships underlying the supply of the climate regulation ecosystem service.

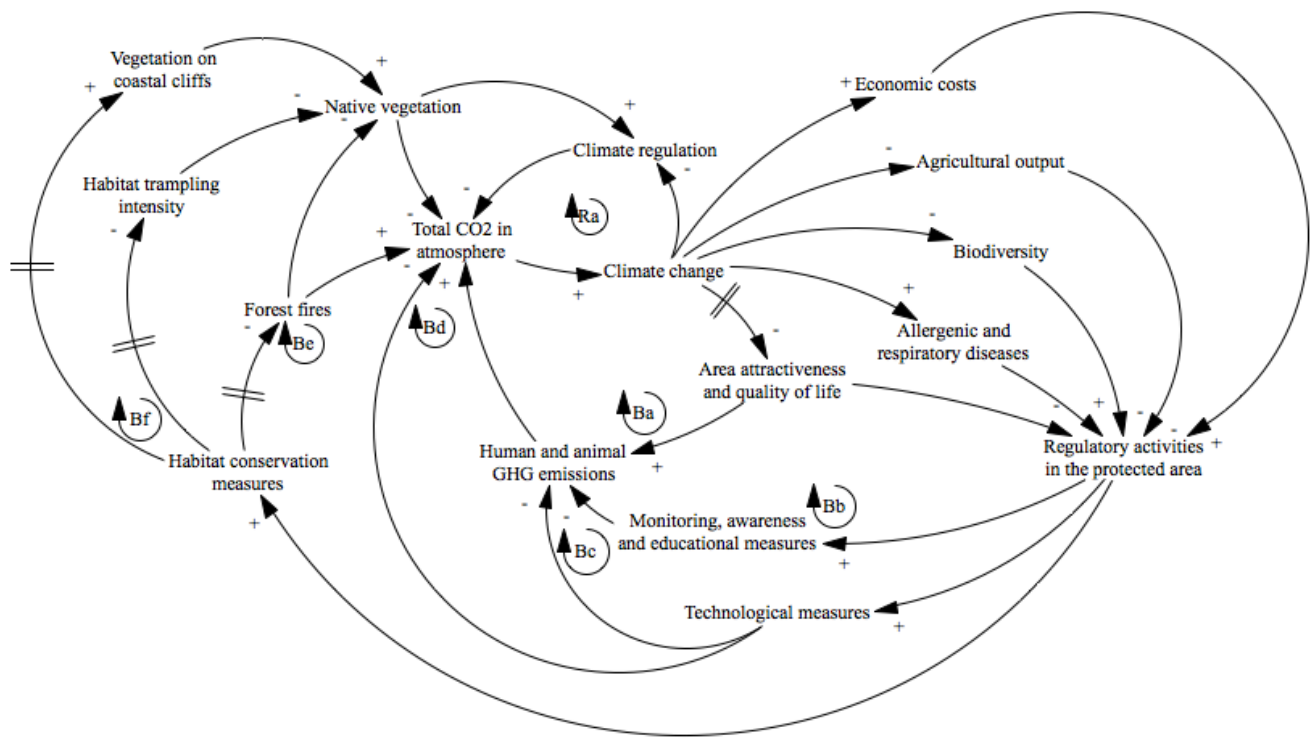

Fig. 4. Climate regulation causal loop diagram. 
From the CLD, we can observe how stakeholders perceived the management of the "climate regulation" service in order to guarantee the supply of the service over the next 20 years. We can also infer how the protected area influences or is influenced by this ecosystem service. The diagram has several feedback loops described below, as well as links established between this service and other categories of ecosystem services (e.g., provision, cultural, support and regulation).

According to participants' perceptions, climate change is deeply connected with climate regulation, forming a reinforcing (Ra). The decrease of climate regulation service leads to an increase of total $\mathrm{CO}_{2}$ in atmosphere, which will increase climate change. In this context the variable "climate change" was perceived as an aggregated measure of a number of extreme events and changes in temperature and precipitation. Positive feedback loops indicate reinforcing dynamics that underlies continued growth or decline patterns. In this case, an increase in climate change, all other things equal, will cause a decrease in climate regulation, i.e. as a consequence of climate variability that will affect existing carbon stores, evapotranspiration and GHG emissions [25]. Schröter et al. [28] also point to this reinforcing loop, revealing that climate change feeds back to climate regulation services, while Maani [29] showed how a climate that induces global warming also forms a reinforcing loop.

Balancing loops represent negative feedback showing a resistance or a response to change, aiming for stability and depicting rules, regulations and policy mechanisms, which can provide control or stability in a system. The diagram represented in Fig. 4 has a dominance of balancing loops (e.g., labelled as sets of loops $\mathrm{Ba}, \mathrm{Bb}, \mathrm{Bc}, \mathrm{Bd}, \mathrm{Be}$ and $\mathrm{Bf}$ ) demonstrating a typical structure of a CLD depicting a management process. These loops show different management options to maintain the capacity of ecosystems to provide climate regulation services over the next 20 years, for example through the carbon storage in the context of the protected area. This causal narrative revolves around two distinct management strategies, one without any intervention by the natural park managers (set of loops $\mathrm{Ba}$ ) and the other with measures aiming for active conservation actions that enable the climate regulation service (set of loops $\mathrm{Bb}, \mathrm{Bc}, \mathrm{Bd}, \mathrm{Be}$, and $\mathrm{Bf})$.

What are the consequences arising from a decrease of the climate regulation service? More total $\mathrm{CO}_{2}$ in the atmosphere, which leads an increase of climate change. All things held equal, with an increase of climate change effects, in the long term and with no intervention, the area will lose attractiveness and quality of life, which will induce a decrease of human and animal GHG emissions (and consequently of the total $\mathrm{CO}_{2}$ in the atmosphere), thus decreasing climate change (set of loops Ba). These negative feedback loops highlight how the system can find its balance in the long term, showing how a self-response to the problem may be triggered, albeit an undesired one from a managers and human well-being point of view. An entry point for these loops could be, for instance, a reduction in the levels of GHG emissions that in some way pacify authorities and cause them not to intervene further, leading to increased levels of carbon emissions. Subsequently, an increase in climate change effects (through the reduction of the climate regulation service) will have different impacts (e.g., economic costs, agricultural outputs decrease, biodiversity loss) that motivate distinct actions and intervention measures.

Economic, social, human health and ecological impacts observed with an increase of climate change lead to an increase of "regulatory activities in the protected area" fostering three key types of answers. One of the actions proposed by participants to endorse a sustainable flow of climate regulation was "monitoring, awareness and educational measures" (Bb), which will induce a decrease of "human and animal GHG emissions" and thus, possibly, the decrease of total $\mathrm{CO}_{2}$ in atmosphere, decreasing climate change and allowing for an intensification of "climate regulation". This set of cycles includes five loops that are similar to each other differing 
only on the impact that motivated it (i.e., economic costs, agricultural output, biodiversity, allergenic and respiratory diseases or area attractiveness and quality of life).

The set of feedback loops Bc and Bd describe technological management mechanisms, and both contain five similar loops. Technological measures can act on emissions directly promoting their reduction $(\mathbf{B c})$; examples of technologies arising as a solution for $\mathrm{CO}_{2}$ mitigation in Portugal are the introduction of renewable energies such as solar photovoltaic rooftops or the biogas from agricultural and animal waste [30], and the use of Carbon Capture and Storage (CCS) technologies in cement industries [31], [32]. Regarding technological measures acting in the direct reduction of total $\mathrm{CO}_{2}$ in the atmosphere $(\mathbf{B d})$, some authors have been describing the addition of biochar (organic material thermally decomposed under limited supply of oxygen) to soils as a means of $\mathrm{CO}_{2}$ sequestration, increasing soil productivity [33].

Finally, "habitat conservation measures" are the third type of options emerging from the increase of "regulatory activities in the protected area". These measures are depicted through two different sets of causal loops (Be and Bf). Local stakeholders' perceptions regarding the drivers of change of climate regulation are mainly focused on land changes, which are aligned with recent literature on ecosystem services assessment [25]. Higher habitat conservation measures will induce less forest fires (Be), which will reduce the $\mathrm{CO}_{2}$ in the atmosphere by increasing the native vegetation that is responsible for $\mathrm{CO}_{2}$ sequestration and by avoiding the amount of $\mathrm{CO}_{2}$ that is emitted to the atmosphere with the burning of biomass. In the Arrábida Natural Park, these measures should counteract abandonment of rural areas, active forest management (e.g., cutting and cleaning), and the introduction of extensive grazing practices in order to decrease the probability that fires ignite inside the Park [34].

The increase of habitat conservation measures will be responsible, after some delay, for the expansion of vegetation areas on coastal cliffs and for the reduction of habitat trampling intensity, both leading to an increase of natural vegetation. This will reduce the total $\mathrm{CO}_{2}$ in the atmosphere and the increase of climate regulation service (Bf).

Hence, the described CLD clearly shows different management options to deal with the climate regulation service. Compared against the reference mode (Figure 2), it is clear that the set of feedback loops $\mathbf{B b}, \mathbf{B c}$ and $\mathbf{B d}$ are related with trends depicted by the red line (GHG emissions, excluding LULUCFs). Intervening on "monitoring, awareness and educational measures" and on "technological measures" promotes the corresponding hopes pathway. Conversely, the set of feedback loops $\mathbf{B e}$ and $\mathbf{B f}$ are linked with the green line (LULUCFs removals), which represents the lion share of the climate regulation service flow, thus allowing the reduction of the net GHG emissions.

Another interesting lesson from the developed CLD is highlighted in Figure 5, concerning the identification of inter-linkages between climate regulation and other ecosystem services. 


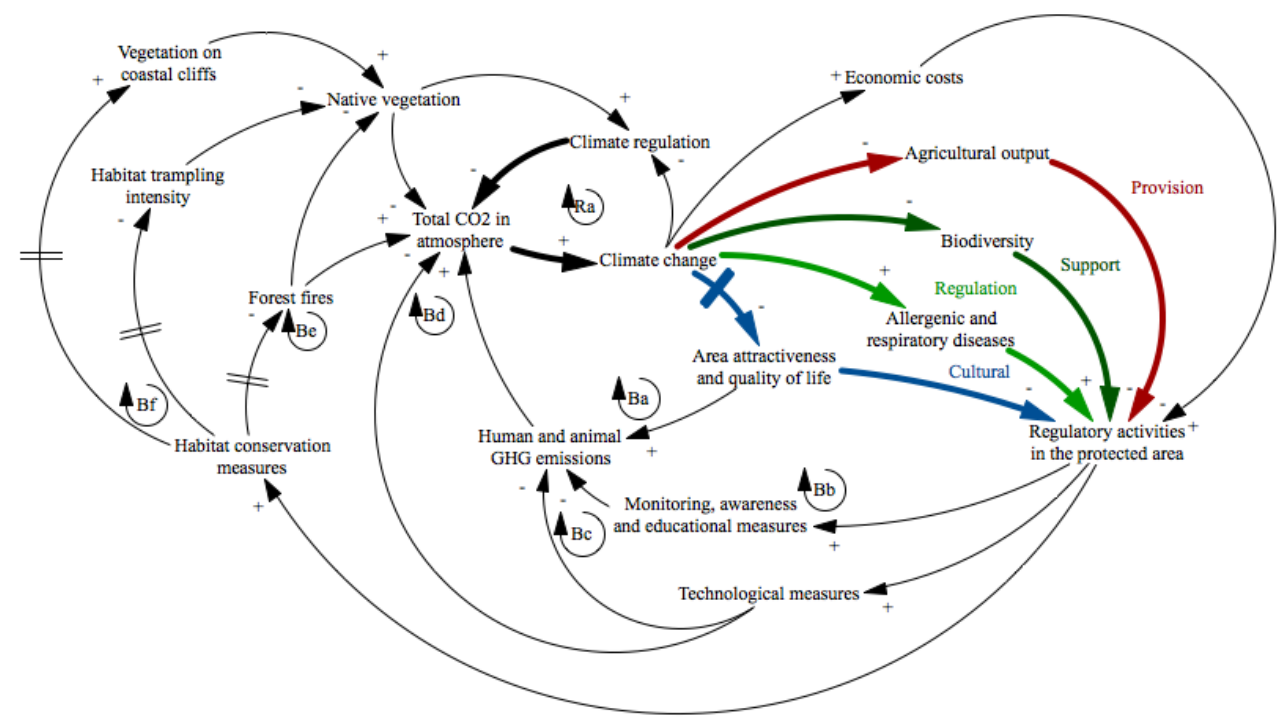

Fig. 5. Causal loop diagram highlighting the links among different categories of ecosystem services.

By explicitly formalising these interrelationships, managers are more likely to understand how the preservation of climate regulation services affects preservation and management of other ecosystem services. The red causal link portrays the representation of provision services, here exemplified by food production (agricultural output). According to participants, the increase in climate change will lead to a decrease of agricultural output. The dark green arrow represents support services - increasing effects of climate change will increase the threats to biodiversity. Climate regulation also interacts with services from the same category since, through a decrease in climate change which leads to a reduction of allergenic and respiratory diseases (depicted by the light green arrow). Cultural services are represented in Fig. 5 through the variable "area attractiveness and quality of life" (and causal links portrayed in blue), which shows a delayed response in the opposite direction as the climate change increases.

This integrated analysis brings forward the argument that the preservation of climate regulation will foster the delivery of other categories of services, which means that the measures identified will also contribute for the sustainable flow of more ecosystem services. Furthermore, the CLD obtained throughout the PSM process reflects participants' understanding of the regulation mechanism underlying this ecosystem service and that they are able to frame it within the local protected area context.

\subsection{Follow up: Developing Indicators for Ecosystem Services Assessment}

As depicted in Fig. 1, results from the proposed PSM approach may be subsequently used in ecosystem services assessment studies. Conceptualizing stakeholders' perceptions on ecosystem services supports an increased shared understanding of the underlying supply and demand side mechanisms. Hence, one of the follow-up options includes the definition of ecosystem services indicators, which may be quantified over time and space and deepen the analysis on the system.

Defining indicators for ecosystem services has been argued as an important research topic since the MEA study [1]. However, some categories of services are more suitable for a process of indicator selection than others. According to Layke [35], regulating and cultural services indicators are much more broadly defined than provisioning indicators, and indicator sets vary 
significantly in their inclusiveness. Thus, to address this knowledge gap, different authors have been working on ways to improve ecosystem services indicators. For example, HernándezMorcillo et al. [36] presented an empirical review of cultural ecosystem services indicators, while Villamagna et al. [37] developed a multi-indicator framework for mapping cultural ecosystem services. According to the TEEB study [2], indicators are variables communicating something of interest or relevance to policy or decision makers with logical connection to the object or the process being measured. When looking for indicators for ecosystem services one of the important criteria is the fitness to the purpose [2], which means setting clear goals (e.g., in the process described above this may translate into having a clear question guiding the development of a CLD) and an understanding of the target audience and their needs (e.g., the stakeholder group invited for the collaborative systems mapping process). Interestingly, some authors have also recently described the use of system dynamics modelling processes to support the definition of ecosystem indicators. That is the case of Vugteveen et al. [38] who developed socio-ecological system indicators using group model building for dealing with mussel fisheries and tourism development in The Netherlands.

In the proposed PSM methodology, we were able to define indicators from the collaborative CLD in order to illustrate follow-up activities. Examples of indicators include the "standing stock of carbon (metric tons/hectare)" and the "value of carbon storage sequestration (million euros)" [1], [35]. These two indicators act on carbon storage and sequestration, leading to a lower concentration of $\mathrm{CO}_{2}$ in the atmosphere. Carbon exchange in the vegetation-soilatmosphere could also contribute for this process. To address measures of habitat conservation, relevant indicators could include the "change in extent of ecosystems coverage (percent)". In synthesis, formalising ways to translate the leverage points into indicators is important when extracting lessons from a PSM process concerned with the different management options for ecosystem services.

\section{Evaluation of The Participatory Systems Mapping Process}

At the end of the workshop, we requested participants to answer a questionnaire aiming to evaluate results of the ecosystem services PSM approach. The questionnaire was developed based on the structure developed by van den Belt [39], [40] and Videira et al. [12]. The questionnaire aimed at evaluating the outcomes at different levels: individual, group, organization and method. The majority of the questions had a closed answer format with statements according to which participants expressed their level of agreement, through a Likert scale ranging from 1 (totally disagree) to 5 (totally agree).

The majority of participants considered that the workshop gathered a diverse group of agents with interest in the area (average score: 4.4). Participants suggested that more residents in the Park and representatives of nature sports activities should be present. The questionnaire revealed that stakeholders agreed that participants functioned as a group during the workshop, thus oriented towards a common goal (average score: 4.8), with open and frontal discussions (average score: 4.8). When asked about the consensus and the discussions to achieve it, participants from the climate regulation group revealed: "good interaction allowing us to achieve a consensus", "interaction close to the ideal", "consensus on the need to guarantee the flow of the service", however "several distinct ideas on how to do it".

Regarding the methodology of CLD construction, $94 \%$ of the participants agreed on the importance and usefulness of the methodology in structuring the discussion and the analysis of ecosystem services provided in the natural park, creating opportunities for everyone to participate in the process. Concerning the systems language used in this methodology, the 
majority of the answers indicated an agreement that the common language helped them to analyse in an integrated form the relevant problems associated with ecosystem services. All participants of the climate regulation working group "agreed" or "totally agreed" on the usefulness of the exchange of ideas to map the relationships underlying this ecosystem service. The discussions during the workshop were constructive and allowed participants to improve knowledge about the ecosystem services of the area (average score: 4.5).

Figure 6 illustrates the results regarding the evaluation of the methodology and individual participant contribution for the outcomes. The results show an average higher than 4 (agreement) in all the presented statements.

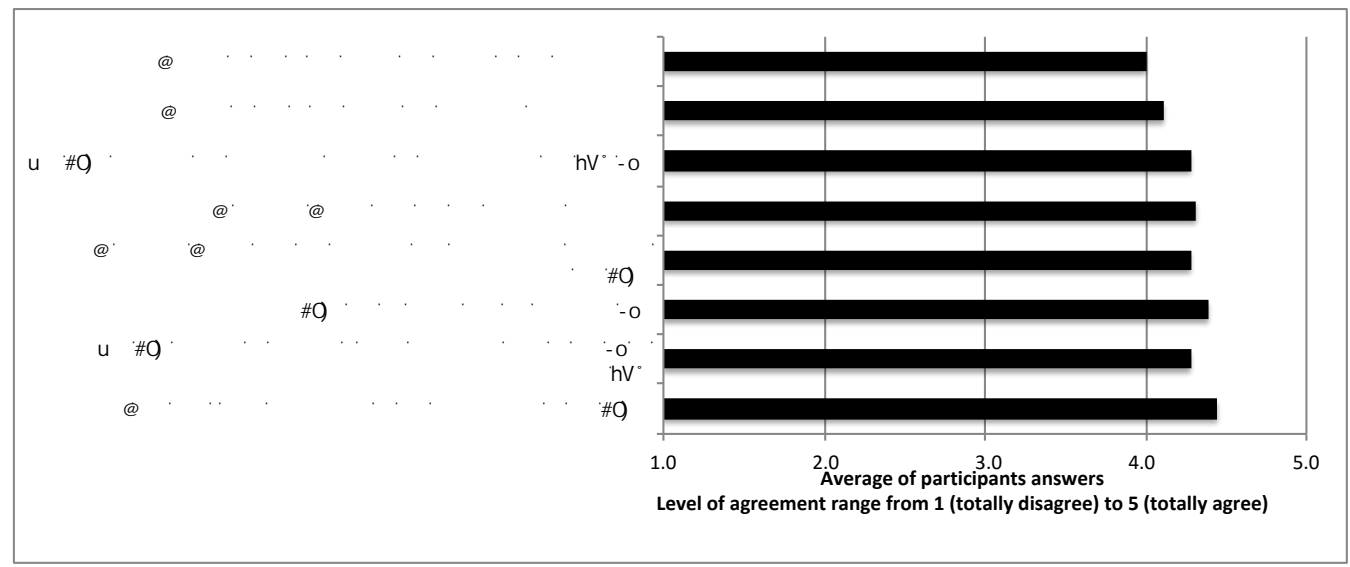

Fig. 6. Evaluation of outcomes from the participatory systems mapping process (average of selected evaluation statements).

The majority of participants $(87.5 \%)$ stated that the workshop was worth the time spent and only $12.5 \%$ answered "in some way", while none of the participants replied negatively to this question. Regarding the positive and negative aspects of the workshop, the comments collected can be organized into broader categories. The identified negative aspects were mainly related with to time available ("little time for final discussion"; "difficulty to manage the time available"; "too much information to discuss during the time"; "need to understand the methodology"). These comments point out the importance of research teams striking a balance between the time available to implement the proposed methodology and the time requested from stakeholders participating on a voluntary basis. Furthermore, only one participant from the climate regulation working group argued that the services were insufficiently adapted to the area. Despite the criticism of this comment, the analysis presented in the previous section shows how management of this ecosystem service could indeed be addressed locally.

The majority of positive comments were related with "sharing" and interaction between participants ("sharing between all the parts"; "sharing of ideas"; "interaction between participants"; "consensus"). Some respondents referred to the "open and active participation of all" the "diversity of people and consequently diversity of options" and the "PSM methodology" that enabled us "to capture the vision of other sectors understanding the measures of unifying the sectors". One participant also referred to the importance of "contributing to the sustainability of the Natural Park" and another one to the "opportunity to deepen the knowledge about ecosystem services". 


\section{CONCLUSION}

This paper presents a structured methodology, based on participatory systems mapping, for the conceptualization of stakeholders' perceptions of ecosystem services. With the increasing calls for using this concept in decision-making processes, the proposed approach advances a platform to involve social actors in the identification of the underlying structure behind the sustainability of ecosystem services flows. The proposed PSM process unfolds in two main steps, namely, a participatory systems mapping workshop followed by postproduction and validation tasks.

The testing of the proposed approach in a case study aimed at eliciting knowledge to support management of a natural area in Portugal, taking the concept of ecosystem services as a basis for the identification and discussion of alternative policies. The PSM workshop had as a guiding question: how to guarantee a sustainable flow of ecosystem services in the protected area over the next 20 years?

The results showed that participants were able to co-produce knowledge, share mental models and bridge perspectives in order to produce a joint CLD. Regarding the climate regulation service, the outcome was very positive, since it was possible to capture stakeholder perceptions of the variables and links explaining the flow of this service in the case of Arrábida Natural Park. Six sets of balancing feedback loops were identified, representing different options for the management of the service. Climate regulation by ecosystems is (partly) provided through the control of $\mathrm{CO}_{2}$ in the atmosphere. Higher levels of carbon emissions can trigger and promote actions by protected area managers to reinforce measures such as habitat conservation programs, technological innovations, monitoring, awareness and educational activities that, over time, are expected to mitigate carbon emissions and contribute to the capacity of the ecosystem to provide climate regulation services. Our approach demonstrated how broad stakeholder groups may be engaged in participatory modelling processes to address such complex issues, collaboratively eliciting perceptions on the feedback structures underlying changes in the provision of ecosystem services, formalizing interrelationships among different categories of services, and exploring solutions to guarantee a sustainable flow of benefits provided by nature to human well-being.

\section{ACKNOWLEDGEMENT}

The authors would like to acknowledge the support of the Portuguese Science Foundation to the PhD fellowship (BD/68846/2010). We are also grateful of the support of CENSE (UID/AMB/04085/2013) and FCT-UNL to workshop materials. We thank ICNF and the Arrábida Natural Park for the help and support during all the process, making it possible to implement the participatory systems making approach; and Casa da Baía for hosting the workshop. We are also thankful to workshop participants, who have generously contributed with their time and knowledge during the development of the case study.

\section{REFERENCES}

[1] Millennium Ecosystem Assessment. Ecosystems and Human Well-being, Synthesis. Island Press, Washington, D.C., 2005, pp. 155.

[2] TEEB. The Economics of Ecosystems and Biodiversity Ecological and Economic Foundations. Edited by Pushpam Kumar. Earthscan, London and Washington, 2010.

[3] Gómez-Baggethun E., de Groot R., Lomas L. P., Montes C. The history of ecosystem services in economic theory and practice: From early notions to markets and payments schemes. Ecological Economics 2010:69(6):1209-1218 doi:10.1016/j.ecolecon.2009.11.007

[4] EU FP7 OpenNESS Project Deliverable 4.1., Gómez-Baggethun E., Martín-López B., Barton D., Braat L., Saarikoski H., Kelemen E., García-Llorente M., van den Bergh J., Arias P., Berry P., L., Potschin M., Keene H., 
Dunford R., Schröter-Schlaack C., Harrison P. State-of-the-art report on integrated valuation of ecosystem services. European Commission FP7, 2014.

[5] Lopes R., Videira N. Valuing marine and coastal ecosystem services: An integrated participatory framework. Ocean \& Coastal Management 2013:84:153-162. doi:10.1016/j.ocecoaman.2013.08.001

[6] Martín-López B., Gómez-Baggethun E., García-Llorente M. Trade-offs across value-domains in ecosystem services assessment. Ecological Indicators 2014:37:220-228. doi:10.1016/j.ecolind.2013.03.003

[7] Hisschemöller M., Hoppe R. Coping with Intractable Controversies: The Case for Problem Structuring in Policy Design and Analysis. In: Knowledge, Power, and Participation in Environmental Policy Analysis. Transaction Publishers, New Brunswick and London, 2001, pp. 47-72.

[8] Funtowicz S., Ravetz J. Science for the post-normal age. Futures 1993:25:739-755. doi:10.1016/00163287(93)90022-L

[9] Antunes P., Stave K., Videira N., Santos R. Using participatory system dynamics in environmental and sustainability dialogues. In: Handbook of Research Methods and Applications in Environmental Studies. Edward Elgar Publishing, Cheltenham, UK, 2015, pp. 346-374. doi:10.4337/9781783474646

[10] Videira N., Antunes P., Santos R. Scoping river basin management issues with participatory modeling: the Baixo Guadiana experience. Ecological Economics 2009:68:965-978. doi:10.1016/j.ecolecon.2008.11.008

[11] Sedlacko M., Martinuzzi A., Ropke I., Videira N., Antunes P. Participatory systems mapping for sustainable consumption: Discussion of a method promoting systemic insights. Ecological Economics 2014:106:33-43. doi:10.1016/j.ecolecon.2014.07.002

[12] Videira N., Lopes R., Antunes P., Santos R., Casanova J. Mapping maritime sustainability issues with stakeholders groups. Systems Research and Behavioral Science 2012:29:596-619. doi:10.1002/sres.2141

[13] Videira N., Schneider F., Sekulova F., Kallis G. Improving understanding on degrowth pathways: An exploratory study study using collaborative causal models. Futures 2014:55:58-77. doi:10.1016/j.futures.2013.11.001

[14] Forrester J. W. World Dynamics. Productivity Press, Portland, 1971.

[15] Lane D. C. The Emergence and Use of Diagramming in System Dynamics: A Critical Account. Systems Research and Behavioral Science 2008:25:3-23. doi:10.1002/sres.826

[16] Sterman J. D. Business Dynamics. Systems Thinking and Modeling for a Complex World. Irwin McGraw-Hill: New York, 2010.

[17] Polasky S., Carpenter S., Folke C., et al. Decision-making under great uncertainty: environmental management in an era of global change. Trends in Ecology \& Evolution 2011:26(8):398-404. doi:10.1016/j.tree.2011.04.007

[18] Lal R. Soil carbon sequestration impacts on global climate change and food security. Science 2004:304(5677):1623-1627. doi:10.1126/science.1097396

[19] Lopes R., Videira N. Collaborative scoping of ecosystem services in marine and coastal protected areas: The case of Arrábida Natural Park. Presentation at European Society for Ecological Economics, University of Leeds, UK, 30 June - 3 July, 2015.

[20] Vennix J. Group Model-Building: Facilitating Team Learning Using System Dynamics. John Wiley \& Sons: Chichester, 1996.

[21] Hovmand P. S., Rouwette E. A. J. A., Andersen D. F., Richardson G. P., Kraus A. Scriptapedia 4.0.6, 2013.

[22] Fumega P. R. Arrábida and its natural hazards. Master's Thesis, Faculdade de Letras da Universidade de Coimbra, 2014.

[23] EEA. Coring Land Cover 2006. European Environment Agency, 2006.

[24] EC. European Union Transation Log, Verified Emissions. European Commission, Climate Action. [Online]. Available: http://ec.europa.eu/environment/ets/

[25] The UK National Ecosystem Assessment: Synthesis of the Key Findings. UNEP-WCMC, LWEC, UK, 2014.

[26] APA. National emissions Inventory - Common report format. Agência Portuguesa do Ambiente, 2015.

[27] Otto P., Struben J. The "standard method": Scripts for a group model building intervention. Proceedings of the 21st International System Dynamics Conference, New York, July 2003.

[28] Schröter D., et al. Ecosystem service supply and vulnerability to global change in Europe. Science 2005:310:13331337. doi:10.1126/science. 1115233

[29] Maani K. Decision-making for climate change adaptation: a systems thinking approach. National Climate Change Adaptation Research Facility, Gold Coast, 2013, pp. 66.

[30] Seixas J., Fortes P., Dias L., Dinis R., Alves B., Gouveia J. P. Simões S. Low Carbon RoadMap: Portugal 2050 Energy and Waste Greenhouse emissions. Study for the Executive Committee of the Climate Change Commission. E-value, SA and FCT-UNL of New University of Lisbon, Lisbon, Portugal, 2012.

[31] Gouveia J. P., Seixas J., Labriet M., Fortes P., Gargiulo M. Prospective Scenarios for the Adoption of CCS Technologies in the Iberian Peninsula. Sustainable Energy Technologies and Assessments 2013:2:31-41. doi:10.1016/j.seta.2013.02.002

[32] Seixas J., Fortes P., Dias L., Carneiro J., Mesquita P., Boavida D, Aguiar R., Marques F., Fernandes V., Helseth J., Ciesielska J., Whiriskey K. $\mathrm{CO}_{2}$ Capture and storage in Portugal: a bridge to a low carbon economy. Universidade Nova de Lisboa. Faculdade de Ciências e Tecnologia, Lisboa, 2015. 
[33] Lehmann J., Joseph S. Biochar for Environmental Management: An Introduction. [Online]. Available: http://www.biochar-international.org/images/Biochar_book_Chapter_1.pdf.

[34] ICN. Management Plan of Arrábida Natural Park. Instituto de Conservação da Natureza, February 2003.

[35] Layke C. Measuring Nature's Benefits: A Preliminary Roadmap for Improving Ecosystem Service Indicators. WRI Working Paper. World Resources Institute, Washington DC [Online]. Available: http://www.wri.org/project/ ecosystem-service-indicators

[36] Hernández-Morcillo M., Plieninger T., Bieling, C. An empirical review of cultural ecosystem service indicators. Ecological Indicators 2013:29:434-444. doi:10.1016/j.ecolind.2013.01.013

[37] Villamagna A. M., Mogollón B. Angermeier P. L. A multi-indicator framework for mapping cultural ecosystem services: The case of freshwater recreational fishing. Ecological Indicators 2014:45:255-265. doi:10.1016/j.ecolind.2014.04.001

[38] Vugteveen P., Rouwette E., Stouten H., van Katwijk M., Hanssen L. Developing socio-ecological system indicators using group model building. Ocean \& Coastal Management 2015:109:29-39. doi:10.1016/j.ocecoaman.2015.02.011

[39] Van den Belt M. Mediated modeling: a collaborative approach for the development of shared understanding and evaluation of environmental policy scenarios. With case studies in the Fox River Basin, Wisconsin and the Ria Formosa, Portugal. Ph.D. dissertation. University of Maryland, 2000.

[40] Van den Belt M. Mediated Modeling: A System Dynamics Approach to Environmental Consensus Building, Island Press: Washington DC, 2004.
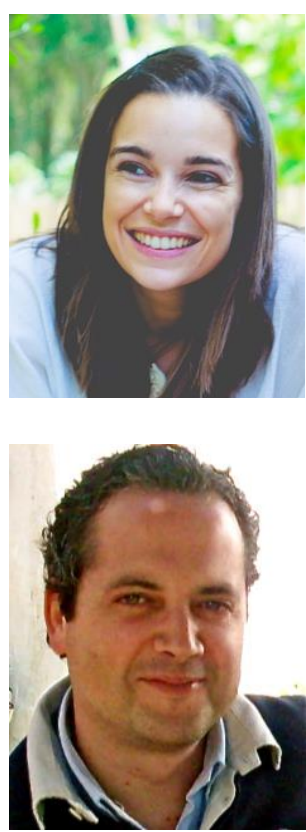

Rita Lopes is a PhD student at CENSE - Center for Environmental and Sustainability Research, in a joint $\mathrm{PhD}$ program on Climate Change and Sustainable Development Policies from Universidade NOVA de Lisboa and Universidade de Lisboa. She received the MSc degree in Environmental Engineering from Universidade NOVA de Lisboa (2008). Her research focuses on ecosystem services valuation and participatory approaches. The research aims to articulate the different value dimensions of ecosystem services to support decision-making processes through participatory platforms integrating different tools.

ORCID ID: orcid.org/0000-0002-2467-788X

Nuno Videira has a $\mathrm{PhD}$ in environmental engineering from Universidade NOVA de Lisboa and a MPhil in system dynamics from the University of Bergen. Currently he is Assistant Professor at the Department of Environmental Sciences and Engineering of NOVA's School of Science and Technology (FCT), collaborating on ecological economics, environmental management, participatory methods and integrated modelling courses. He is a member of the ECOMAN - Ecological Economics and Environmental Management group of the Center for Environmental and Sustainability Research (CENSE, FCT NOVA). His research focuses on participatory system dynamics modelling approaches for stakeholder engagement in sustainability decisions, with recent applications to ecosystem services, degrowth pathways and sustainable consumption topics. He is currently member of the board of the European Society for Ecological Economics (ESEE).

ORCID ID: orcid.org/0000-0002-4514-1996 